\title{
O BNDES E O CONFLITO ENTRE TRANSPARÊNCIA E SIGILO BANCÁRIO E EMPRESARIAL
}

\author{
Jonathan Barros Vita* \\ Nilo Trindade Braga Santana**
}

\section{RESUMO:}

O artigo tem por objeto o estudo dos limites do sigilo bancário e empresarial na concessão de empréstimos pelo Banco Nacional de Desenvolvimento Econômico e Social (BNDES), a partir da contraposição entre o dever de transparência da Administração Pública e os direitos fundamentais à intimidade e livre iniciativa. Através do método dedutivo e revisão bibliográfica, analisou-se as normas constitucionais envolvidas, a evolução da transparência nas operações de empréstimos do referido banco público, além de importante julgado do Supremo Tribunal Federal (STF) sobre o tema, traçando-se ao fim, alguns limites aos direitos fundamentais em confronto.

PALAVRAS-CHAVE: Transparência; Livre Iniciativa; Sigilo Bancário; Sigilo Empresarial; Bancos Públicos de Desenvolvimento.

\section{THE BNDES AND THE CONFLICT BETWEEN TRANSPARENCY AND BANK BUSINESS SECRECY}

\begin{abstract}
:
This article aims to study the limits of banking and business secrecy in the granting of loans by the National Bank for Economic and Social Development (BNDES), based on the contrast between the duty of transparency of the Public Administration and the fundamental rights to privacy and free enterprise. Through the deductive method and bibliographic review, were analyzed the constitutional rules involved, the evolution of transparency in this loan operations of the aforementioned public bank, besides an important decision of the Federal Supreme Court (STF) on the subject, in order to draw some limits to the fundamental rights in conflict.
\end{abstract}

KEY WORDS: Transparency; Free Enterprise; Bank Secrecy; Business Secrecy; Public Development Banks.

\section{INTRODUÇÃO}

\footnotetext{
*Pós doutorado pela Wirtschaftsuniversität, Viena/Áustria. Mestre/Doutor em Direito PUC/SP. Mestre em segundo nível pela universidade comercial luigi Bocconi, Milão/Italia. Professor titular e Coordenador do Programa de Mestrado/Doutorado da UNIMAR.

*** Mestrando em Direito pelo MINTER UNIMAR-U:VERSE. Procurador do Estado do Acre.
} 
O dever de transparência da Administração Pública bem como a cidadania enquanto fundamento da República Federativa do Brasil decorrem do próprio modelo de Estado adotado na Constituição da República Federativa do Brasil (CRFB), qual seja, o modelo de Estado Democrático de Direito. Todavia, um Estado constitucional e democrático pressupõe também a existência de direitos e garantias fundamentais, dentre os quais se insere, no caso brasileiro, o direito à intimidade e à livre iniciativa e liberdade de concorrência.

O presente artigo visa estudar o confronto dos valores apontados acima no contexto da concessão de empréstimos pelo Banco Nacional de Desenvolvimento Econômico e Social

(BNDES). Tratando-se o BNDES de um banco público de fomento através do qual um montante cada vez maior de recursos públicos, como será visto nos itens seguintes, tem sido utilizado para a concessão de empréstimos com vistas ao desenvolvimento econômico e social do País, a transparência em suas operações tem especial relevância, especialmente como instrumento para o controle externo, quer pelo Poder Legislativo com auxílio dos Tribunais de Contas, quer pela própria população através do exercício da cidadania ativa. Todavia, ao dever de transparência em suas operações, contrapõe-se o direito ao sigilo bancário e empresarial dos agentes econômicos privados tomadores de empréstimo.

Para desenvolver o objeto de pesquisa, estuda-se, na seção 1, os contornos constitucionais dos valores em questão para que, posteriormente, seja possível uma adequada análise de como solucionar seu confronto quando da concessão de empréstimos pelo BNDES. Na seção 2, passa-se a analisar a evolução do grau de transparência do BNDES ao longo do tempo, identificando-se uma grande alteração em sua política de transparência a partir do ano de 2015. Ainda nessa seção, procedeu-se à importante distinção entre a formulação de políticas públicas com vistas à promoção do desenvolvimento econômico e social através da concessão de empréstimos - decisão política sobre os setores a serem financiados, prioridades, diretrizes, dentre outras - e a execução de tais políticas previamente formuladas através da efetiva concessão de empréstimos pelo BNDES, bem como, esclareceu-se as razões pelas quais se escolheu apenas a execução de tais políticas como objeto do presente estudo. Por fim, na seção 3, passou-se à análise do leading case julgado pelo Supremo Tribunal Federal (STF) no Mandado de Segurança 33.340/DF e sua relevância para o confronte entre o dever de transparência e o dever de sigilo na concessão de empréstimos pelos BNDES. 


\section{1 - DO PRINCÍPIO DA TRANSPARÊNCIA E DO DIREITO FUNDAMENTAL À INTIMIDADE E À LIVRE INICIATIVA.}

A Constituição da República Federativa do Brasil (CRFB) indica a cidadania e a livre iniciativa como fundamentos do Estado Brasileiro, ao lado de outros como a soberania e a dignidade da pessoa humana:

Art. $1^{\circ}$ A República Federativa do Brasil, formada pela união indissolúvel dos Estados e Municípios e do Distrito Federal, constitui-se em Estado Democrático de Direito e tem como fundamentos:

I - a soberania;

II - a cidadania;

III - a dignidade da pessoa humana;

IV - os valores sociais do trabalho e da livre iniciativa;

$\mathrm{V}$ - o pluralismo político.

Sendo o controle do poder político uma das dimensões em que a cidadania $^{1}$ se manifesta (COMPARATO, 1.993), pode-se concluir que a observância do dispositivo acima exige do Estado brasileiro uma atuação transparente, que permita à sua população efetivo acompanhamento e controle social da gestão da coisa pública, o que incluiria também a destinação de recursos públicos.

Em consonância com o disposto acima, a CRFB consagra a exigência de transparência na condução da coisa pública no caput de seu art. 37, especialmente no que tange ao princípio da publicidade, nele expressamente previsto:

Art. 37. A administração pública direta e indireta de qualquer dos Poderes da União, dos Estados, do Distrito Federal e dos Municípios obedecerá aos princípios de legalidade, impessoalidade, moralidade, publicidade e eficiência e, também, ao seguinte:

$[\ldots]$.

A transparência na gestão da coisa pública revela-se como importante instrumento não apenas para possibilitar o efetivo exercício da cidadania através do controle social do poder político, como visto acima, como ainda para dar efetividade ao teor prescritivo do enunciado jurídico que indica ser o Estado brasileiro um Estado Democrático de Direito (CRFB, art. $\left.1^{\circ}\right)$.

Nesse sentido, Moreira Neto (2014, p. 89), após diferenciar responsividade e responsabilidade, associando o último à realização do Estado de Direito e o primeiro à realização do Estado Democrático de Direito, que ultrapassaria a ideia de mera vinculação a

\footnotetext{
${ }^{1} \mathrm{O}$ autor indica que a cidadania em um Estado social deve instaurar-se em cinco níveis, dentre os quais insere o controle do poder político, ultrapassando assim uma concepção de cidadania liberal-individualista.
} 
uma legalidade estrita que marcaria o Estado de Direito e a ideia de responsabilidade, aponta que:

Finalmente, acrescente-se, a sindicabilidade da responsividade dependerá também da qualidade do que se tem denominado de transparência (ou visibilidade) da gestão administrativa e, por isso, a publicidade é igualmente instrumental tanto para a responsabilidade quanto para a responsividade.

Desse modo, evidencia-se a importância da transparência na gestão da coisa pública, quer como decorrência direta do princípio da publicidade que deve reger a Administração Pública, quer como decorrência de o Estado brasileiro constituir-se em Estado Democrático de Direito e ter a cidadania como um de seus fundamentos. A contraparte do dever da Administração, e por conseguinte do gestor público, de atuar de modo transparente e com respeito ao princípio da publicidade pode ser vista como o direito do administrado de obter informações junto à Administração, quer sejam elas de interesse individual, quer sejam de interesse coletivo. Tal direito encontra previsão expressa na CRFB em seu art. $5^{\circ}, \mathrm{XXXIII}$, no art. $37, \S 3^{\circ}$, II e no art. $216, \S 2^{\circ}$ e foram regulamentados através da Lei n. 12.257/2011, popularmente conhecida como Lei de Acesso à Informação (LAI).

Embora fuja ao escopo do presente artigo uma análise detida sobre o conteúdo da LAI, cumpre ao menos transcrever o teor de seu art. $3^{o}$ que corrobora a importância da transparência e do acesso à informação como instrumento de controle social da administração pública, o que, por conseguinte, possibilita um efetivo exercício de cidadania e contribui para a configuração do Estado brasileiro como Estado Democrático de Direito:

Art. $3^{\circ}$ Os procedimentos previstos nesta Lei destinam-se a assegurar o direito fundamental de acesso à informação e devem ser executados em conformidade com os princípios básicos da administração pública e com as seguintes diretrizes: I - observância da publicidade como preceito geral e do sigilo como exceção;

II - divulgação de informações de interesse público, independentemente de solicitações;

III - utilização de meios de comunicação viabilizados pela tecnologia da informação; IV - fomento ao desenvolvimento da cultura de transparência na administração pública;

V - desenvolvimento do controle social da administração pública.

Para além de corroborar a importância do acesso à informação e da transparência na gestão da coisa pública, como instrumental para um efetivo exercício da cidadania e concretização de um estado democrático e de direito, o dispositivo supratranscrito aponta ainda para a necessidade de divulgação das informações de interesse público independentemente de solicitação, bem como, impõe o uso da tecnologia de informação como instrumento de maximização da transparência, a permitir amplo e fácil acesso a uma grande 
coletividade de administrados, através, por exemplo, da rede mundial de computadores. É nesse contexto que será avaliado, na seção seguinte, se o BNDES, através de seu site oficial, utiliza-se de modo adequado da tecnologia da informação como ferramenta potencializadora para a divulgação de informações de interesse público e para a concretização do dever de transparência.

Por fim, ainda quanto ao artigo $3^{\circ}$ da LAI, supratranscrito, observa-se da leitura de seu inciso I que, embora a publicidade seja a regra, existem situações em que o sigilo revela-se razoável ou mesmo necessário, com vistas à tutela de outros valores e princípios constitucionais. No mesmo sentido, o art. 22 da LAI dispõe expressamente:

Art. 22. O disposto nesta Lei não exclui as demais hipóteses legais de sigilo e de segredo de justiça nem as hipóteses de segredo industrial decorrentes da exploração direta de atividade econômica pelo Estado ou por pessoa física ou entidade privada que tenha qualquer vínculo com o poder público.

Desse modo, evidencia-se que a Lei de Acesso a Informação não afasta nem, de nenhum modo, revoga, ou mesmo limita, a aplicação da Lei Complementar no 105/2001, que regulamenta o sigilo bancário, isto é, o sigilo das operações de instituições financeiras. Considerando que o objeto do presente artigo é analisar como compatibilizar o dever de transparência na gestão da coisa pública e na gestão de recursos públicos com o respeito aos direitos fundamentais de preservação da intimidade e da livre iniciativa na regulação da transparência do BNDES na concessão de empréstimos, faz-se necessário tecer algumas considerações sobre o sigilo bancário e empresarial.

Os sigilos bancário e empresarial não podem ser analisados de modo dissociado do direito fundamental à preservação da intimidade (art. $5^{\circ}, \mathrm{X}$ da CRFB) e à livre iniciativa como fundamento da ordem econômica constitucional (art. 170, caput, da CRFB) e da própria República Federativa do Brasil (art. $1^{\circ}$, IV da CRFB).

Assim dispõe o art. $5^{\circ}, \mathrm{X}$ :

Art. $5^{\circ}$ Todos são iguais perante a lei, sem distinção de qualquer natureza, garantindo-se aos brasileiros e aos estrangeiros residentes no País a inviolabilidade do direito à vida, à liberdade, à igualdade, à segurança e à propriedade, nos termos seguintes:

$[\ldots]$

X - são invioláveis a intimidade, a vida privada, a honra e a imagem das pessoas, assegurado o direito a indenização pelo dano material ou moral decorrente de sua violação;

$[\ldots]$. 
A inviolabilidade da intimidade e da vida privada, por sua vez, não pode ser dissociada da livre iniciativa como fundamento não apenas da ordem econômica constitucional, mas também da própria República Federativa do Brasil, como apontado anteriormente. Nessa linha, o sigilo revela-se como ferramenta não apenas da preservação da vida privada dos administrados, mas também, como instrumento de concretização dos valores da livre iniciativa e da liberdade de concorrência ${ }^{2}$, ocasião em que recebe a alcunha de sigilo empresarial $^{3}$ e não perde a sua natureza de direito fundamental. No mesmo sentido, entendeu um Ministro do Supremo Tribunal Federal (STF) ao relatar o Mandado de Segurança 33.340 como se depreende do seguinte trecho de seu voto, extraído do inteiro teor do respectivo acórdão de julgamento (2015, p. 12-13):

É cediço que o sigilo empresarial é fundamental para o livre exercício de uma atividade econômica. Trata-se de preocupação universal destinada a assegurar credibilidade e estabilidade ao sistema bancário e empresarial. A divulgação irresponsável de dados sigilosos de uma sociedade empresária pode, por razões naturais, inviabilizar a exploração de uma atividade econômica ou expor, indevidamente, um grupo econômico, na medida em que os competidores passam a ter acesso a informações privilegiadas que não deteriam numa situação normal. A proteção estatal ao sigilo bancário e empresarial deve ser, nesse contexto, compreendida como corolário da preservação à intimidade assegurada pelo art. $5^{\circ}$, inciso X, da Carta da República [...].

Desse modo, restou evidenciado que a constituição brasileira impõe uma gestão transparente da coisa pública e, por conseguinte, dos recursos públicos, como ferramenta de concretização quer do princípio da publicidade expressamente previsto no caput do art. 37 da CRFB, quer da própria cidadania e do modelo de estado democrático de direito, prescrito no art. $1^{\circ}$ da CRFB. Todavia, diante da consagração da intimidade, e de seus corolários como o sigilo bancário e o sigilo empresarial, como verdadeiro direito fundamental, torna-se pertinente perquirir como compatibilizar os valores em questão, quando da concessão de empréstimos a agentes econômicos privados, por bancos públicos de fomento.

Estando o objeto do artigo delimitado especificamente à questão da transparência na concessão de empréstimos pelo BNDES, passa-se, na seção seguinte, a analisar seu objeto de atuação e a evolução no grau de transparência dos empréstimos por ele concedidos.

\footnotetext{
${ }^{2}$ A liberdade de concorrência é prevista na CRFB no art. 170, IV, como princípio que rege a ordem econômica constitucional.

${ }^{3}$ Ao lado do sigilo empresarial, também o sigilo bancário pode servir de ferramenta à concretização dos valores da livre iniciativa e da liberdade de concorrência, quando titularizado por agente econômico.

${ }^{4} \mathrm{O}$ referido Mandado de Segurança será analisado mais detalhadamente na seção 3 do presente artigo.
} 


\title{
2 O BNDES E A EVOLUÇÃO NA TRANSPARÊNCIA DE SUAS OPERAÇÕES.
}

O Banco Nacional do Desenvolvimento Econômico e Social (BNDES) foi criado em 1.952, através da Lei $\mathrm{n}^{\mathrm{o}} 1.628$, ainda com o nome de Banco Nacional do Desenvolvimento Econômico (BNDE). $\mathrm{O}$ art. $8^{\circ}$ da referida lei indicava, de modo genérico, o objeto de atuação:

Art. $8^{\circ}$ Para dar execução aos objetivos desta Lei, bem como da Lei $n^{\circ} 1.518$, de 24 de dezembro de 1951 e do art. $3^{\circ}$ da Lei $\mathrm{n}^{\circ} 1.474$, de 26 de novembro de 1951, é criado, sob a jurisdição do Ministério da Fazenda, o Banco Nacional do Desenvolvimento Econômico, que também atuará, como agente do Govêrno, nas operações financeiras que se referirem ao reaparelhamento e ao fomento da economia nacional.

O BNDE foi classificado como empresa pública pela Lei $n^{0} 5.662 / 1971$, como se depreende da leitura de seu art. $1^{\mathrm{o}}$ :

\begin{abstract}
Art. $1^{\circ}$ O Banco Nacional do Desenvolvimento Econômico (BNDE), autarquia federal criada pela Lei $\mathrm{n}^{\circ} 1.628$, de 20 de junho de 1952, fica enquadrado, nos termos e para os fins do $\S 2^{\circ}$ do art. $5^{\circ}$ do Decreto-lei $n^{\circ} 200$, de 25 de fevereiro de 1967, na categoria de empresa pública, dotada de personalidade jurídica de direito privado e patrimônio próprio, com a denominação de Banco Nacional do Desenvolvimento Econômico (BNDE) e vinculação ao Ministério do Planejamento e Coordenação Geral, nos termos do art. 189 do Decreto-lei no 200, de 25 de fevereiro de 1967.
\end{abstract}

A atual denominação (BNDES) é dada pelo art. $5^{\circ}$ do Decreto Lei n ${ }^{\circ}$ 1.940/1982 que institui o FINSOCIAL, a ser administrado pelo banco público: "O Banco Nacional do Desenvolvimento Econômico (BNDE) passa a denominar-se Banco Nacional de Desenvolvimento Econômico e Social (BNDES)".

Sendo objeto do presente estudo a atuação do BNDES como instrumento de fomento ao desenvolvimento através de concessão de empréstimos, é importante observar que tal atuação tem variado ao passar dos anos. Nesse sentido, como observa Mencarini (2015), enquanto nos primeiros anos o foco da atuação se deu nas áreas de energia elétrica, infraestrutura, transporte e produção de aço, sua atuação foi se diversificando ao longo do tempo, tendo sido durante a década de 70 "fundamental para a finalização do processo de industrialização de substituição de importação coordenada pelo Estado, por meio de financiamentos, direcionamento de poupança para bens de capital, empréstimos para projetos e programas de desenvolvimento regional” (2015, p. 150). Nos anos 80, o BNDES passa por um recuo em sua atuação devido à crise por que passou o Estado brasileiro, bem como à elevada dívida externa, voltando sua atuação a ter destaque na economia nacional na década de 90, quando o Banco passa a atuar eminentemente nos processos de desestatização de 
empresas públicas, voltando nos anos 2000 a focar no fomento econômico por meio do financiamento de agentes privados (MENCARINI, 2015, p. 150-152).

A importância do BNDES no fomento ao desenvolvimento nacional e as mudanças no foco de sua atuação ao longo do tempo são bem sintetizadas por Garcia (2011, p. 11):

O BNDES, criado em 1952, passou por transformações nas diferentes gestões governamentais e dinâmicas da economia brasileira e mundial. Ele atuou desde a consolidação do modelo de substituição de importações, até os processos de privatizações no Brasil, financiando parcial ou integralmente capitais estrangeiros e nacionais na aquisição das empresas estatais. A importância do Banco em termos de volumes é crescente, não somente para economia brasileira: desde 2005 o volume de créditos do BNDES aumentou 391\% e é maior do que o Banco Mundial, sendo que somente em 2010 concedeu 3,3 vezes mais que o Bird (US\$ 96,32 bilhões).

Embora fuja ao escopo do presente artigo perquirir acerca da relevância efetiva do BNDES como impulsionador do desenvolvimento econômico e social nacional, o expressivo aumento dos valores emprestados, bem como a comparação desses valores com dois importantes bancos internacionais de fomento como mencionado na transcrição acima, revelam o potencial impacto da atuação do referido banco público na economia nacional, o que confere relevo ao debate acerca da transparência em sua atuação.

\subsection{DELIMITANDO O OBJETO DE ESTUDO: DA FORMULAÇÃO E DA EXECUÇÃO DE POLÍTICAS PÚBLICAS ATRAVÉS DA CONCESSÃO DE EMPRÉSTIMOS COM RECURSOS PÚBLICOS}

Como visto acima, o foco de atuação do BNDES tem variado ao longo do tempo, isto é, a partir de uma diretriz básica, fomento ao desenvolvimento econômico e social, cada governo pode definir quais os principais setores a serem fomentados e quais as estratégias a serem utilizadas, tudo com vistas à promoção do desenvolvimento econômico e social. Um estudo aprofundado sobre tais escolhas e sobre eventual falta de transparência nos critérios utilizados ultrapassaria o objeto do presente artigo, tratando-se tais escolhas de escolhas eminentemente políticas, o que, embora não impossibilite o seu controle em caso de violação, por exemplo, ao princípio da razoabilidade, relaciona-se muito mais a escolhas políticas sobre modelos e projetos de desenvolvimento, avaliados, ao menos em teoria, no momento do sufrágio eleitoral.

Desse modo, embora se possa argumentar que defender a total impossibilidade de controle sobre tais decisões implicaria em defender a existência de um governo sob império do arbítrio, o que violaria frontalmente a art. $1^{\mathrm{o}}$ da Constituição que impõe ao Estado 
brasileiro a sua formatação como Estado de Direito, resta evidente que a natureza e os limites deste controle diferem em muito do controle que é estudado no presente artigo. Ou seja, não se busca aqui estudar as possibilidades e limites de controle na definição das políticas públicas, decisão de natureza eminentemente política, mas sim, estudar o controle de sua execução. Em outros termos, estuda-se no presente artigo as relações entre a transparência do BNDES na concessão de empréstimos e as possibilidades de controle social e legislativo nessas operações.

Embora, como antedito, ultrapasse o objeto da presente pesquisa o estudo do controle e transparência na definição das políticas públicas, isto é, na escolha de estratégias, prioridades e linhas de atuação do BNDES com vistas a promover o desenvolvimento econômico e social, cumpre trazer um breve esclarecimento sobre o tema antes de se passar à análise da transparência na execução de tais políticas, previamente traçadas pelo Poder Legislativo e pelo próprio governo.

A atuação do BNDES encontra-se vinculada inicialmente à própria Lei que o criou (Lei $\left.n^{\circ} 1.628 / 1952\right)$ e alterações correlatas. Desse modo, a primeira escolha de diretrizes na atuação do banco de fomento é feita pelo Poder Legislativo através de ato normativo infraconstitucional, cujo detalhamento maior ou menor terá repercussão no grau de autonomia na atuação do Poder Executivo.

A título exemplificativo, a Lei $\mathrm{n}^{0} 1.628 / 1952$ regulava e delimitava a atuação do BNDES especialmente em seus artigos 11 e 12, deixando ampla margem de regulamentação a ser instrumentalizada através do regimento interno, além de autorizar, no art. 12, VIII, o banco público a "efetuar, sempre que autorizado em lei, outras operações visando ao desenvolvimento da economia nacional” (BRASIL, 1952). A lei no 2.973/1956, por sua vez, aponta expressamente uma ordem de prioridade a ser seguida pelo Conselho de Administração do banco quando da elaboração de seu Orçamento de Investimento, como se depreende da leitura de seu artigo 25 (BRASIL, 1956):

Art. 25. O Orçamento de Investimento, de que trata o artigo anterior, fixará a quota destinada a cada um dos setores de atividades econômicas mencionadas nas Leis $\mathrm{n}^{\circ} \mathrm{s}$ 1.474 , de 26 de novembro de 1951 (art. $3^{\circ}$ ), 1.518, de 24 de dezembro de 1951, e 1.628 , de 20 de junho de 1952, e nesta Lei, com observância da seguinte ordem de prioridade:

I - reaparelhamento e ampliação do sistema ferroviário;

II - reaparelhamento e ampliação de portos e de sistemas de navegação;

III - construção e ampliação de sistemas de energia elétrica;

IV - instalação e ampliação de indústrias básicas; 
V - construção e ampliação de armazéns, silos, matadouros e frigoríficos;

VI - desenvolvimento da agricultura, compreendendo eletrificação rural, inclusive mediante aproveitamento acessório de pequenas quedas d'água;

VII - outros setores.

$\S \mathbf{1}^{\circ}$ A quota destinada a um setor poderá ser transferida para outro, se não houver, em estudo e com viabilidade de deferimento, qualquer projeto de financiamento nele enquadrado.

Da leitura do dispositivo acima, pode-se observar que o legislador, através de escolha eminentemente política, decidiu à época materializar uma ordem de prioridade através de Lei, reduzindo, assim, a margem de discricionariedade política na atuação do Poder Executivo.

A Lei $\mathrm{n}^{\circ}$ 5.662/1971 transformou o BNDE em empresa pública e transformou as normas legais ainda vigentes que tratavam do Banco em normas estatutárias, dispondo ainda o modo de sua alteração - Decreto Executivo (BRASIL, 1971):

Art. $2^{\circ}$ Os dispositivos legais vigentes ou parcialmente modificados da Lei $n^{\circ} 1.628$, de 20 de junho de 1952, e da Lei n ${ }^{\circ}$ 2.973, de 26 de novembro de 1956, constituem, no seu conjunto, o Estatuto pelo qual se rege a empresa pública Banco Nacional do Desenvolvimento Econômico (BNDE), regulando os fins da empresa e a sua estrutura administrativa, bem como os seus órgãos de direção e de controle.

Parágrafo único. As alterações do Estatuto referido neste artigo, necessárias ao funcionamento da empresa, serão feitas, posteriormente à data desta lei, através de decreto do Presidente da República, que será arquivado no Registro do Comércio competente.

Da leitura do dispositivo acima, pode-se concluir que a Lei $\mathrm{n}^{0}$ 5.622/1971 representou uma ampliação na discricionariedade política do Poder Executivo na definição de diretrizes e estratégias de atuação do Banco para fomentar o desenvolvimento econômico (posteriormente desenvolvimento econômico e social), de modo que, por simples Decreto Executivo do Presidente da República, seria possível ampliar, reduzir, ou alterar prioridades, estratégias, dentre outros delineamentos da atuação do banco de fomento em questão.

Foi nesse contexto que durante o "governo Lula"5 editou-se o Decreto n $6.322 / 2007$, alterando diversos dispositivos do Estatuto então vigente e incluindo a possibilidade de concessão de empréstimos para financiar a aquisição de ativos no exterior:

Art. $1^{\circ}$ Os arts. $9^{\circ}, 10,11,13,15,17,20,22-A, 25$ e 29 do Estatuto Social do Banco Nacional de Desenvolvimento Econômico e Social-BNDES, aprovado pelo Decreto $\mathrm{n}^{\mathrm{o}} 4.418$, de 11 de outubro de 2002, passam a vigorar com a seguinte redação:

Art. 9ํㅡ $\mathrm{O}$ BNDES poderá também:

\footnotetext{
${ }^{5}$ Expressão utilizada para indicar o período iniciado em $1^{\circ}$ de janeiro de 2002 e encerrado em 31 de dezembro de 2011, durante o qual Luiz Inácio Lula da Silva foi presidente do País.
} 
II - financiar a aquisição de ativos e investimentos realizados por empresas de capital nacional no exterior, desde que contribuam para o desenvolvimento econômico e social do País;

[...].

A utilização de recursos do BNDES em operações realizadas no exterior (política de estímulos à exportação das campeãs nacionais) gerou grande polêmica durante os governos do PT (ROSSI, 2018). A situação era agravada pela baixa transparência do teor desses empréstimos, como será visto no subitem seguinte. Todavia, o que se busca evidenciar no presente tópico é a distinção entre o objeto principal da pesquisa, a efetiva concessão de empréstimos pelo banco de acordo com as diretrizes e estratégias previamente definidas, e a discricionariedade política na definição de tais diretrizes e estratégias, isto é, na escolha de como fomentar o desenvolvimento econômico e social, priorizando, por exemplo, o direcionamento de recursos para um ou outro setor da economia, ou mesmo, para obras e serviços realizados no exterior.

Em suma, através especialmente de Lei, Decretos e Estatuto da Empresa Pública ora analisada (BNDES), delimita-se o âmbito e modo de atuação do banco de fomento, isto é, delimita-se a política pública a ser executada pela instituição. Como visto acima, as decisões sobre a estratégia a ser adotada, sobre a definição de prioridades, dentre outras, com vistas ao fomento do desenvolvimento econômico e social é tomada pelo governo, dentro do âmbito de sua discricionariedade política, que pode ser majorada ou reduzida a depender do arcabouço legislativo então vigente. Não sendo o objeto do presente estudo perquirir sobre a transparência e o controle acerca do exercício dessa discricionariedade política, pelas razões anteriormente expostas, resta avançar sobre o objeto principal do artigo: a análise do grau de transparência do BNDES ao executar as políticas públicas indicadas pelo governo, isto é, o grau de transparência do BNDES na concessão de empréstimos.

\subsection{A TRANSPARÊNCIA NAS OPERAÇÕES DE CONCESSÃO DE CRÉDITO REALIZADAS PELO BNDES}

Ao analisar a evolução histórica da transparência (acesso à informação) na atuação do BNDES, Mencarini (2015, p.151) conclui que "houve forte ausência de transparência e prestação de contas, mais especificamente, no período militar e início da década de 1980, durante o período de redemocratização". 
O debate acerca da transparência na concessão de empréstimos pelo BNDES foi incrementado com uma nova mudança no foco de atuação do banco, especialmente a partir de 2003, quando o estatuto do Banco foi alterado, permitindo a criação de "linha de crédito específica para internacionalização das empresas brasileiras" desde que estas contribuam para o desenvolvimento social e econômico brasileiro (GARCIA, 2011, p.11).

O direcionamento de empréstimos para obras a serem realizadas em outros Países, ainda que teoricamente visassem o fortalecimento de empresas nacionais e tivessem como baliza o desenvolvimento social e econômico brasileiro, sem que os cidadãos tenham acesso aos valores e juros aplicados nesses empréstimos, gera uma legítima desconfiança acerca dos riscos de uso político do Banco Público. O debate acerca do risco de uso político de bancos públicos de desenvolvimento é bem sintetizado por Lazzarini et al (2014, p. 2) quando aduz que "defendants of development banks emphasize their role in reducing capital constraints and fostering productive investment; detractors point out that they may benefit politically connected capitalists or bail out inefficient firms ${ }^{6,}$

Tal situação, de forte ausência de transparência, começa a mudar a partir de 2015, como aponta Rossi (2018):

[...] o banco, de fato, mantinha muitos dados em segredo e se recusava a fornecer informações. Mas, a partir de 2015, após grande pressão da imprensa e de órgãos de controle, o BNDES se tornou mais transparente - passou a divulgar detalhes sobre seus empréstimos, não só os atuais, mas também os passados, englobando as operações feitas durante os governos do PT.

Essa mudança no grau de transparência do BNDES se dá em especial a partir do julgamento pelo STF do Mandado de Segurança 33340/DF e, embora algumas informações ainda permaneçam em sigilo (a exemplo da análise de risco dos tomadores), já é possível obter-se, no próprio site do banco, informações acerca dos empréstimos realizados, das taxas de juros utilizadas, prazo de pagamento, garantias, dentre outras, além de cópia do próprio instrumento contratual de empréstimo (ROSSI, 2018).

Atualmente, o site do BNDES na rede mundial de computadores (BNDES, 2019) possui, em seu menu principal, um link exclusivo para a transparência e outro para o acesso de informações. Na página relativa à transparência, é possível realizar a consulta de operações do BNDES, pesquisando-se projetos por Estado, setor, ou mesmo por país, no caso de

\footnotetext{
${ }^{6}$ Os defensores dos bancos de desenvolvimento enfatizam seu papel na redução de restrições de capital e na promoção de investimentos produtivos; os detratores apontam que eles podem beneficiar capitalistas politicamente conectados ou socorrer empresas ineficientes [tradução livre].
} 
exportação de obras no exterior, sendo possível, inclusive, acessar a própria versão digital dos instrumentos de contrato de empréstimos realizados, dentre outras informações relevantes, a exemplo da destinação dos recursos oriundos do Tesouro Nacional. Ademais, o banco, em consonância com o que dispõe o art. $3^{\circ}$, II da LAI, analisado na seção anterior, tem procurado promover a transparência ativa, passando a disponibilizar em seu site, sem a necessidade de solicitação, feita com base na referida Lei de Acesso à Informação, os dados mais requisitados pelos administrados:

\begin{abstract}
A política do banco é de evitar retrabalho, neste sentido quando um pedido é realizado mais de uma vez há automaticamente a iniciativa de trabalhar a informação internamente para que seja disponibilizada na transparência ativa. A ideia é de evitar parar a área operacional para o atendimento de solicitações via LAI. Com estas iniciativas é possível notar internamente que com o cotidiano há avanços internos para uma nova cultura de transparência, houve também melhoria do diálogo entre as áreas (MENCARINI, 2015, p. 188).
\end{abstract}

Todavia, alguns documentos permanecem inacessíveis ao grande público, em atendimento aos direitos fundamentais ao sigilo bancário e empresarial analisados na seção anterior, especialmente aqueles utilizados pelo banco público para analisar a viabilidade de concessão dos empréstimos:

Há sigilo de documento, dado e informação quando ocorre solicitação de informações presentes nos Relatórios de Análises, documentos utilizados para a viabilização de empréstimos. Nestes documentos constam informações de mercado relevantes como as estratégicas do planejamento financeiro e comercial dos tomadores de empréstimos, portanto, são informações que disponibilizadas podem ser acessadas por empresas concorrentes. (MENCARINI, 2015, p. 188).

Diante do exposto, é possível concluir-se que, especialmente a partir de 2015, o BNDES aumentou significativamente sua transparência, passando a divulgar não apenas os valores e taxas contratadas, como ainda o próprio instrumento contratual que materializou a operação de empréstimo, em versão digitalizada. Dada a importância do julgamento do Mandado de Segurança 33.340/DF nessa mudança de atuação do banco público, passa-se a analisá-lo em seção destacada.

\title{
3 DO JULGAMENTO DO MANDADO DE SEGURANÇA 33.340/DF PELO STF.
}

O referido Mandado de Segurança 33.340/DF foi impetrado pelo próprio BNDES em face de suposto ato coator praticado pelo Tribunal de Contas da União (TCU), materializado em decisão proferida no bojo da Tomada de Contas 007.527/2014-4 que determinara ao banco 
público "o envio de documentos específicos referentes às operações realizadas entre o BNDES e o Grupo JBS/Friboi” (2015 p. 7). O Banco justificava que os poucos documentos que não haviam sido enviados ao TCU estariam resguardados por sigilo bancário e empresarial. Embora tenha sido reconhecida a impossibilidade de o TCU determinar diretamente a quebra de sigilo, prevaleceu o entendimento de que o envio ao TCU de informações relativas a operações realizadas pelo BNDES não configuraria quebra de sigilo.

Ao abordar o conflito que se estabelecia entre a preservação da intimidade e o princípio da transparência que rege a Administração Pública, o Ministro Relator aduziu que (BRASIL, 2015):

No campo da teoria jurídica, a preservação, in casu, do sigilo das operações realizadas pelo BNDES e BNDESPAR com terceiros não, apenas, impediria a atuação constitucionalmente prevista para o TCU, como, também, representaria uma acanhada, insuficiente, e, por isso mesmo, desproporcional limitação ao direito fundamental de preservação da intimidade.

Se na primeira seção abordamos o controle da administração pública sob a perspectiva da cidadania e, portanto, tratou-se de um controle social, passível de exercício, ao menos em tese, por todos os administrados, o trecho colacionado acima trata de outra modalidade de controle, o controle externo da administração pública, exercido pelo Poder Legislativo com auxílio do respectivo Tribunal de Contas.

Nesse sentido, no que tange à União, estabelece a CRFB em seu art. 70 que:

Art. 70. A fiscalização contábil, financeira, orçamentária, operacional e patrimonial da União e das entidades da administração direta e indireta, quanto à legalidade, legitimidade, economicidade, aplicação das subvenções e renúncia de receitas, será exercida pelo Congresso Nacional, mediante controle externo, e pelo sistema de controle interno de cada Poder.

Quanto ao auxílio do Tribunal de Contas no exercício do controle da Administração Pública Federal, dispõe o caput do art. 71 da constituição brasileira que "O controle externo, a cargo do Congresso Nacional, será exercido com o auxílio do Tribunal de Contas da União, ao qual compete $[. .$.$] ". Regramento semelhante é aplicável aos demais entes federados, como se$ depreende da simples leitura dos arts. 31 e 75 do texto constitucional.

A importância dos tribunais de contas no controle externo da Administração Pública é destacada por Mendes e Branco (2017, p. 1.526):

No Brasil, tal como em determinados países da Europa ocidental (Portugal, Espa $\square$ nha, Itália, França e Bélgica), adotou $\square$ se um sistema de controle externo que tem 
por base os Tribunais de Contas. O modelo baseado nos Tribunais de Contas contrasta com o das Controladorias ou Auditorias $\square$ Gerais, típico dos países de colonização inglesa (Es $\square$ tados Unidos, Austrália, Canadá e Nova Zelândia), incluindo o próprio Reino Unido. O primeiro é exercido por um órgão colegiado com funções de julgamento das contas e de responsabilização dos gestores públicos. O segundo é exercido por um órgão unipessoal que exerce apenas a funções de físcalização. Existe, ainda, um terceiro modelo, misto, de órgãos colegiados, mas sem funções de julgamentos das contas. Trata $\square$ se do modelo presente na Alemanha, na Áustria, nos Países Baixos e também na União Europeia (Tribunal de Contas Europeu).

Retomando a análise do julgamento em questão, diversos outros trechos apontam para uma suposta prevalência da transparência como instrumento de controle da Administração Pública em face da preservação da intimidade. Nesse sentido, os próprios itens 3 e 4 da ementa do julgado, podem levar à incorreta conclusão de que o entendimento consagrado no referido julgamento foi o de que estaria o direito à intimidade fadado a perecer sempre que confrontado com o princípio da transparência da Administração Pública (2015, p. $1-2)$ :

3. O sigilo de informações necessárias para a preservação da intimidade é relativizado quando se está diante do interesse da sociedade de se conhecer o destino dos recursos públicos.

4. Operações financeiras que envolvam recursos públicos não estão abrangidas pelo sigilo bancário a que alude a Lei Complementar $n^{\circ} 105 / 2001$, visto que as operações dessa espécie estão submetidas aos princípios da administração pública insculpidos no art. 37 da Constituição Federal. Em tais situações, é prerrogativa constitucional do Tribunal [TCU] o acesso a informações relacionadas a operações financiadas com recursos públicos.

Todavia, não se pode perder de vista que o objeto do processo em questão se restringia a debater o acesso do Tribunal de Contas aos dados que, de acordo com o entendimento do banco público impetrante, estariam protegidos pelo sigilo bancário e empresarial. É exata e unicamente nesse contexto que os Ministros da Primeira Turma do STF consagraram o entendimento de que tais dados não estariam protegidos pelos sigilos bancário e empresarial de sorte que: 1- deveriam ser remetidos ao Tribunal de Contas da União e; 2 sua requisição direta pelo Tribunal de Contas da União não configurava quebra de sigilo, não havendo, portanto, que se falar em violação à reserva de jurisdição ${ }^{7}$.

Nesse sentido, não se pode extrair do julgado o entendimento de que os documentos em questão, atinentes especialmente à análise feita pelo banco público previamente à

\footnotetext{
${ }^{7}$ Há de se registrar que tal conclusão teve por base a dinâmica probatória própria do rito do Mandado de Segurança, bem como a existência de divergência parcial tendo em vista o teor do voto vencido do Ministro Roberto Barroso que concedia parcialmente a ordem.
} 
concessão do empréstimo, e que envolvem muitas vezes dados cuja ampla divulgação pode prejudicar o exercício da liberdade econômica dos agentes privados tomadores dos empréstimos, a exemplo dos dados constantes dos Relatórios de Análise mencionados na seção anterior, devam ser amplamente disponibilizados aos administrados em geral. Tal ponto é expressamente debatido pelos Ministros, como se extrai do seguinte trecho do inteiro teor do acórdão em questão (2015, p. 36):

O SENHOR MINISTRO LUIZ FUX (RELATOR) - Ministro Luís Roberto, apenas uma pequena observação. O SENHOR MINISTRO LUÍS ROBERTO BARROSO (RELATOR) - Claro! O SENHOR MINISTRO LUIZ FUX (RELATOR) - Todo o voto levou em consideração - e, até, esclareci isso à Ministra Rosa, conversei com ela sobre isso -, quer dizer, o que, em primeiro lugar, me chamou a atenção: são duas pessoas praticamente de direito público litigando entre si. Segundo lugar, eu parti da premissa de que o TCU não vai..., ele quer para ele, para ele exercer a sua função. A ideia é essa. Eu não fiz nenhum juízo de valor sobre isso no voto, claro. Mas a ideia que me parece é essa. O SENHOR MINISTRO LUÍS ROBERTO BARROSO (RELATOR) - Vossa Excelência está partindo da premissa de que essas informações serão mantidas sob sigilo no TCU. O SENHOR MINISTRO LUIZ FUX (RELATOR) - É, se elas estiverem sob sigilo, ou não há nenhum interesse do TCU, pelo que eu entendi, o TCU quer exercer a sua função nesse caso concreto.

Outra não é a conclusão que se extrai da leitura da parte dispositiva do voto do Relator (2015, p. 21):

Ex positis, e na esteira do parecer do Ministério Público Federal acostado aos autos e da jurisprudência consolidada desta Corte de que inexiste garantia de sigilo oponível ao TCU em relação a operações bancárias financiadas com recursos de origem pública, DENEGO a segurança, com resolução do mérito, restando prejudicado o exame do pedido de medida liminar, por não entrever qualquer irregularidade na determinação do TCU que obriga o fornecimento de informações sigilosas contidas em operações realizadas pelas Impetrantes, na medida em que imprescindíveis para o desempenho regular do controle financeiro dos Impetrantes pela Corte de Contas da União.

De todo o exposto, pode-se concluir que o julgamento em questão, ainda que tenha servido de marco histórico para uma mudança na política de transparência do BNDES, como verificado na seção anterior, não consagrou um total desprestígio à livre iniciativa e à liberdade concorrencial, tendo em vista que o sigilo bancário e empresarial dos tomadores de empréstimo junto ao BNDES, embora tenham se revelado inoponíveis ao TCU, sob pena de inviabilizar-se o exercício das competências constitucionais do referido órgão, não foram de todo afastados. Desse modo, a adoção do entendimento consagrado no julgamento do MS 33.340/DF não implica na necessidade de ampla divulgação de documentos que estejam em posse do BNDES e que possam violar de modo desproporcional o sigilo bancário e 
empresarial dos agentes econômicos privados tomadores de empréstimo junto ao referido banco público.

\section{CONCLUSÕES}

A atuação da Administração Pública submete-se ao princípio da transparência, quer em decorrência de expressa previsão constante do art. 37 da CRFB quanto ao princípio da publicidade, quer em decorrência de o Estado brasileiro constituir-se em um Estado Democrático de Direito tendo a cidadania como um de seus fundamentos, como se depreende da leitura do art. $1^{\circ}$ da constituição brasileira. Todavia, o mesmo texto constitucional consagra a liberdade individual que se expressa, inclusive, na seara econômica através da livre iniciativa que é, ao mesmo tempo, fundamento do próprio Estado brasileiro e da ordem econômica constitucional, e através da livre concorrência. Nesse contexto, os sigilos bancário e empresarial do agente econômico privado evidenciam-se como verdadeiros direitos fundamentais que devem ser compatibilizados com o dever de transparência na gestão da coisa pública, na análise de cada caso concreto.

No caso objeto do presente artigo, concessão de empréstimos pelo BNDES, concluiu-se que o banco público em comento apresentou grande evolução no grau de transparência, especialmente a partir do ano de 2015. Concluiu-se ainda que os sigilos bancário e empresarial dos tomadores de empréstimo não podem ser oponíveis pelo banco público em face do TCU de modo a deixar de enviar documentos que o Tribunal de Contas necessite para realização de sua tarefa constitucional de controle externo da Administração Pública, ainda que tais documentos possuam informações sensíveis que, acaso amplamente divulgadas, prejudicariam a liberdade de concorrência dos tomadores, não se podendo concluir, todavia, que esteja o BNDES obrigado a ofertar livre acesso dessas informações aos Administrados em geral.

Desse modo, pode-se concluir que, embora esteja o BNDES obrigado a fornecer ao TCU todas as informações que se façam necessárias para que o órgão exercite o controle da gestão da coisa pública, avaliando inclusive os critérios utilizados para a concessão ou não concessão de determinado empréstimo, no que tange à divulgação de tais informações ao público em geral, deve o Banco resguardar informações que digam respeito unicamente aos agentes econômicos privados e possam vulnerar seu direito fundamental ao sigilo bancário e empresarial. Tal restrição, todavia, não permite a negativa de acesso à informação sobre a 
destinação dada aos recursos públicos, de modo que, atualmente, o BNDES oferece amplo acesso não apenas aos empréstimos realizados, às taxas de juros aplicadas, como inclusive à própria versão digitalizada do instrumento contratual.

\section{REFERÊNCIAS}

BRASIL. [Constituição (1988)]. Constituição da República Federativa do Brasil de 1988. Brasília, DF: Presidência da República, [2019]. Disponível em: http://www.planalto.gov.br/ccivil_03/constituicao/constituicao.htm. Acesso em: 12 abr. 2020.

BRASIL. Decreto-Lei no 1.940 , de 25 de maio de 1982. Institui contribuição social, cria o Fundo de Investimento Social (FINSOCIAL) e dá outras providências. Disponível em: https://www2.camara.leg.br/legin/fed/declei/1980-1987/decreto-lei-1940-25-maio-1982365639-publicacaooriginal-1-pe.html. Acesso em: 30 out. 2019.

BRASIL. Lei $\mathbf{n}^{\mathbf{0}}$ 1.628, de 20 de junho de 1952. Dispõe sobre a restituição dos adicionais criados pelo art. $3^{\circ}$ da Lei $n^{\circ} 1.474$, de 26 de novembro de 1951, e fixa a respectiva bonificação; autoriza a emissão de obrigações da Dívida Pública Federal; cria o Banco Nacional do Desenvolvimento Econômico; abre crédito especial e dá outras providências. Disponível em: http://www.planalto.gov.br/ccivil_03/LEIS/1950-1969/L1628.htm. Acesso em: 30 out. 2019.

BRASIL. Lei $\mathbf{n}^{0}$ 2.973, de 26 de novembro de 1956. Prorroga a vigência das medidas de ordem financeira relacionadas com a execução do Plano de Desenvolvimento Econômico previstas nas Leis $\mathrm{n}^{\circ} 1.474$, de 26 de novembro de 1951, e 1.628, de 20 de junho de 1952, e dá outras providências. Disponível em: http://www.planalto.gov.br/ccivil_03/LEIS/19501969/L2973.htm. Acesso em: 22 nov. 2019.

BRASIL. Lei ${ }^{\circ}$ 5.662, de 21 de junho de 1971. Enquadra o Banco Nacional do Desenvolvimento Econômico (BNDE) na categoria de emprêsa pública, e dá outras providências. Disponível em: http://www.planalto.gov.br/ccivil_03/LEIS/L5662.htm. Acesso em: 30 out. 2019.

BRASIL. Lei $\mathbf{n}^{\circ} \mathbf{1 2 . 5 2 7}$, de 18 de novembro de 2011. Regula o acesso a informações previsto no inciso XXXIII do art. $5^{\circ}$, no inciso II do $\S 3^{\circ}$ do art. 37 e no $\S 2^{\circ}$ do art. 216 da Constituição Federal; altera a Lei $n^{\circ} 8.112$, de 11 de dezembro de 1990; revoga a Lei ${ }^{\circ}$ 11.111, de 5 de maio de 2005, e dispositivos da Lei $\mathrm{n}^{\circ} 8.159$, de 8 de janeiro de 1991; e dá outras providências. Disponível em: http://www.planalto.gov.br/ccivil_03/_ato20112014/2011/lei/112527.htm. Acesso em: 30 out. 2019.

BRASIL. Supremo Tribunal Federal. Mandado de Segurança 33.340/DF: Inteiro Teor do Acórdão, 49 fls. 26 maio 2015. Disponível em:

http://portal.stf.jus.br/processos/downloadPeca.asp?id=307284475\&ext=.pdf. Acesso em: 30 out. 2019.

COMPARATO, Fábio Konder. A nova cidadania. Lua Nova: Revista de Cultura e Política. São Paulo, n. 28-29, p. 85-106, abr. 1993. Disponível em: http://www.scielo.br/scielo.php?script=sci_arttext\&pid=S0102$64451993000100005 \& \operatorname{lng}=$ en\&nrm=iso. Ácesso em: 30 out. 2019. 
GARCIA, Ana S. Políticas públicas e interesses privados: a internacionalização de empresas brasileiras e a atuação internacional do governo Lula. In: ENCONTRO NACIONAL ABRI, 3., 2011, São Paulo. Proceedings online [...]. Associação Brasileira de Relações Internacionais Instituto de Relações Internacionais - USP. 2011. Disponível em: http://www.proceedings.scielo.br/scielo.php?pid=MSC0000000122011000100015\&script=sci _arttext\&tlng=pt. Acesso em: 30 out. 2019.

LAZZARINI, Sergio G. et al. What do development banks do? Evidence from BNDES, 2002-2009. maio 2014. Disponível em:

https://papers.ssrn.com/sol3/papers.cfm?abstract_id=1969843. Acesso em: 30 out. 2019.

MENCARINI, Fabrizio. Transparência nos bancos públicos brasileiros: um estudo sobre a implementação da Lei de Acesso à Informação (LAI) no Banco do Brasil (BB), Caixa Econômica Federal (CEF) e Banco Nacional de Desenvolvimento Econômico e Social (BNDES). 232 f. Dissertação (Mestrado em Direito) - (CMAPG) - Escola de Administração de Empresas de São Paulo, São Paulo, 2015. Disponível em:

https://bibliotecadigital.fgv.br/dspace/handle/10438/13602. Acesso em: 30 out. 2019.

MENDES, Gilmar Ferreira; BRANCO, Paulo Gustavo Gonet. Curso de Direito Constitucional. 12. ed. rev. atual. São Paulo: Saraiva, 2017.

MOREIRA NETO, Diogo de Figueiredo. Curso de direito administrativo: parte introdutória, parte geral e parte especial. 16. ed. rev. e atual. Rio de Janeiro: Forense, 2014.

ROSSI, Amanda. Existe uma "caixa-preta" do BNDES, como diz Bolsonaro? BBC News Brasil, São Paulo, nov. 2018. Disponível em: https://www.bbc.com/portuguese/brasil46267698. Acesso em: 30 out. 2019. 